\title{
Action Research to Overcome the Stress Caused by the Combination of Academic and Work Life of Korean Early Childhood Education Doctoral Students
}

\author{
Mikyung Kim ${ }^{1, *}$ \\ ${ }^{1}$ School of Early Childhood Education, Chongshin University, Seoul, Korea \\ *Correspondence: School of Early Childhood Education, Chongshin University, Seoul, Korea. Sadang ro 143, \\ Dongjak Ku, Korea. Tel: 1-822-3479-0372. E-mail: kinder999@hanmail.net
}

This study supported by Chongshin University

Received: September 11, 2019 Accepted: September 30, $2019 \quad$ Online Published: October 17, 2019

doi:10.5430/wje.v9n5p16 URL: https://doi.org/10.5430/wje.v9n5p16

\begin{abstract}
The purpose of this action study is to take a closer look at the factors of stress with doctoral students majoring in early childhood education and to identify changes through the process of overcoming them. As a starting point, in order to do that, two Korean doctoral students (Park, Joo-yeon and Kwak, Ji-min) majoring in early childhood education were selected, one is a nursery director and the other is a college lecturer. In - depth interviews, journal writing, and quantitative analysis were used as data collection methods. Park Joo-yeon has chosen internal resource to get up early in the morning to study for classes and to exercise. Kwak, Ji-min has chosen internal resource to travel, study in café, and to exercise. Park, Joo-yeon chose two methods as external resources. One pointed out emotional support as a warm word of comfort and encouragement, and the other pointed out physical support to reduce household chores through sharing with her husband. On the other hand, Kwak, Ji-min did not choose external resources. One conclusion we can draw from this process was that not only two doctoral students' stress and stress response were alleviated but also overcoming power increased through the process of overcoming them. Proceeding from this fact, we could logically assume that overcoming power were effective in individual ability and acceptance of life.
\end{abstract}

Keywords: action research, stress, overcome, doctoral student, early childhood education

\section{Introduction}

I miss a student who looks at me with bright, sparkling eyes trying not to miss one of my doctoral classes. The doctoral students majoring in early childhood education sit down in exhausted, sometimes sleep. It is a routine to teach those who want to finish the class quickly. General opinion's starts to make out that teaching and learning also take place in this process, but this is not what 1 wants. I want to understand their weary minds. A majority of the doctoral students who take classes are students and have jobs. They are students, colleagues, nursery teachers/directors, or part time lecturer at work, and mother, wife, daughter in law, and daughter at home. They have four or five roles. One person is under tremendous stress because she has to take on too many roles.

As Castle (1997) has shown, interactions between environments, such as excessive competition in the academic environment, complex human relationships, a series of emotional tensions, economic threats, and excessive work, create diverse problems and life stress. Stress is due to an imbalance between individual perceived needs and the ability to utilize resources to meet these needs (Germain \& Gitterman, 1986), and job stress refers to the degree to which individuals' (McCleese et al., 2007).

For example, while listening to a well-prepared student's announcement, a student working as the nursery director suddenly shouted, "It hurts too much," as if she could no longer stand it. She blamed herself for not completing her mission because of her tired mind and heavy work. It was a scream. "You don't' understand, how hard I am now. You don't know how hard I am!" This reaction is one of the psychological responses to the stress that difficulties 
accumulate and that we cannot do what we have done well in the meantime (Baumeister, 1984). Compared to the other occupations, a nursery director must play a variety of roles such as finance, staff, public relations, operational planning, purchasing materials, parental counseling, and administration.

This doctoral student is a nursery director and an adjunct professor at college. The only her daughter is preparing for a special high school entrance exam. She has to do a lot of housework at home. She teaches children in church school on weekends. Also, She must do assignments and research. I don't think the word "cheer up, endure a little" is a fundamental solution in this situation. We usually do not know the background stress imposed on ourselves. Therefore, we don't ignore background stresses because they can have negative effects such as shock stress.

The lack of time for research and intellectual growth reduce my sense of self-esteem and achievement. My reality is becoming increasingly difficult to find a balance between work and school because of uncertainty and anxiety about the future. I also thank my family for believing and supporting me, but I am sorry that I haven't been able to spend time together. This can be a small problem that naturally disappears after graduation. Sometimes, however, these beliefs and support act as a great burden... (Park, Joo-yeon's journal writing, September 19)

As a student, I am chased on because of my assignments, research, lecture preparation, and teaching. The lack of time leads to the lack of sleep. I always live with stress because of this life. I entered a doctoral course to become a good educator and expert. My goal has collapse as soon as I started my doctorate. I hate myself. What am I doing in class? Who am I? I have tried to digest work well until now. As a result, I have tried to do it. But I was exhausted. I felt frustrated by my limitations. This mental stress makes me hard. (Kwak, Ji-min's journal writing, September 11)

As such, Korean doctoral students who strive to become the elite of this era are physically and mentally degraded by stress. Continuous stress can harm students' mental and physical health (Huang et al., 2010). Looking at these students, I recalled that the tree was not meant to bear fruit, but to share. So as a professor, I reflect on my failure to open a new world to my students every day. In Bernard's book 'The God, he described that "We do nothing. Not because it's difficult. "It's hard not to." This statement provided me a key with which to unlock many of the riddle of this situation. My heart beat. I was encouraged by this remark and didn't hesitate to choose the best way to start right away. Dirkx (1989) defined human feelings, thoughts, and behaviors in relation to others as the goal of self-reflection. I also wanted to find out the factors of stress that students have and find ways to overcome them.

The problems faced by Korean early childhood education doctoral students are very different, such as in workplace, academia, and home, relationships with professors and peers that are very personal. Therefore, first, the extraction of common problems is a common approach, and second, the approach to coping with each individual situation, daily life and time is sought for a personal approach. What are the common causes of stress common to doctoral students? And I tried to find out and implement some personal methods that can solve this problem. The purpose of this study is to share the factors of stress emerging from both academics and doctoral students and to focus on coping strategies and to implement a plan to reduce stress. I dreamed of a change, recalling the words of Naughton and Hughes (2008) that "I hope to make a difference and dream of a better world and make a difference due to change." If doctoral students try to overcome stress by understanding and agonizing over the factors, action studies could produce productive results as a starting point for solving this problem because there was no clear answer to this question.

\section{Problem}

I asked to write the journal about the difficulties and stress factors of the students. In analyzing the journals together, I came up with the meaning of the word overcoming while figuring out what difficulties a doctoral student has in common and what the stress is. The meaning of the dictionary of overcoming is to remove or improve the difficult or undesirable state or situation. Therefore, the overcoming method presented by the previous research will not actually guarantee the change of the doctoral students. However, it is a problem of this study that the assumption that the efforts of the doctoral students to identify and cope with the stress factors and the problems caused by themselves are likely to make a difference.

\section{Methodology}

\subsection{Participants}

The background of the participants is shown in the table 1. 
Table 1. Background and Stress of Participants

\begin{tabular}{|c|c|}
\hline Participants & Background and Stress \\
\hline Kwak Ji-min & $\begin{array}{l}\text { She did not get married, She is } 38 \text { years old. She was born in Korea, but she studied music in } \\
\text { Canada from middle school until she finished her doctoral course. However, she liked teaching } \\
\text { students rather than playing as a musician. She returned to Korea and has been working as a } \\
\text { lecture at college after completing doctoral course. She has been teaches music education and } \\
\text { piano for pre-service teachers since } 2009 \text {. Because of this, she was interested in early childhood } \\
\text { education and entered doctoral course. Her main research interests focus on the developing an } \\
\text { effective music teaching model for pre-service early childhood teachers, particularly with regard } \\
\text { to music education for young children. She is very busy with many things daily such as doctoral } \\
\text { students, college lecturer, center English teacher, and private piano lessons. She is getting worse } \\
\text { mentally and physically. She is exhausted. }\end{array}$ \\
\hline Park Joo-yeon & $\begin{array}{l}\text { She is } 43 \text { years old, married and has a daughter and a husband. She has been working as a } \\
\text { nursery director for } 20 \text { years. She is a doctoral student and teaches pre-service teachers for } 9 \\
\text { hours a week. She also visits } 8 \text { nursery schools monthly to conduct consulting on education and } \\
\text { evaluation certification as a consultant. She should prepare for courses work and research } \\
\text { because she is a doctoral student. Her main research interests focus on the developing program } \\
\text { of communication competency for pre-service teachers. She is a perfectionist who has a strong } \\
\text { sense of responsibility and must do whatever it takes to be perfect. But she can't do things } \\
\text { perfectly in time because of the many things that are imposed on her. Because of this, stress is } \\
\text { increasing day by day and often gets angry and nervous. }\end{array}$ \\
\hline
\end{tabular}

\section{Data Collection and Analysis}

The study began with two Korean doctoral students majoring in early childhood education. The data were analyzed using two methodological approaches: qualitative and quantitative. Qualitative analysis data were collected based on participants' academic journals, teaching observation records, group interview and personal interview data. The qualitative data collected were used to analyze the causes of stress in two doctoral students, the choice of coping methods to solve it, and the implementation process of selected stress coping methods. In addition, the members check were provided to see how closely the stress of the two doctoral students was expressed and analyzed.

Quantitative data were analyzed based on a stress, stress response and coping ability questionnaire for two doctoral students. Based on this, we examined the common and personal stress of two doctoral students and selected appropriate coping strategies to overcome stress. It explored paradigm shift of stress through implementation of coping strategies chosen by doctoral students. To this end, the cycle stage of planning-execution-reflection-assessment was applied. The start of the study was attributed to a total of two doctoral students majoring in early childhood education.

The stress evaluation of the quantitative research used stress, stress response, and coping power measurement tools.

\subsection{Stress Measurement Tool}

Stress measurement tool developed by Yoo and his colleagues (2008) was used. This tool is composed of school stress and clinical stress in order to measure the stress of nursing students. However, it is suggested that it is appropriate to measure school stress except clinical stress to early childhood education students. Through the content validity of three professors, Stress instrument was used. The measurement tool consists of 39 items (15 items in the individual, 5 items in the individual, 10 items in the school, and 9 items in the environment). Each item is a Likert 5 -point scale with a score of $0-4$. The higher the score indicated the higher the degree of stress. The reliability of this test tool is Cronbach $\alpha=.93$.

\subsection{Stress Response}

Stress response measurement developed by Kang and Kim (2000) was used. The questionnaire consisted of 39 items (6 items of tension, 4 items of aggression, 3 items of anger, 6 items of anger, 8 items of depression, 5 items of fatigue, and 7 items of frustration) Four points are awarded. The reliability of the test tool was Cronbach $\alpha=.97$.

\subsection{Overcoming Power}

In order to measure the overcoming power, overcoming power measurement a tool developed by Wagnild and Young (1993) was used. The test tool consisted of 25 items (17 items of individual competence, 8 items of self-acceptance). Each item is a Likert 7-point scale and scores of 1-7 points. Reliability is Cronbach $\alpha=.88$. 


\subsection{Action Research Course}

The action research model used in the present study was constructed by using the 'research design model for problem-based execution study' of Lee (2002). The action research was conducted for 10 weeks with two doctoral students. (1week: Identifying stress factors, scheduling and checking for a week, choosing how to execute, 2-5 weeks: $1^{\text {st }}$ action and modification and complement, 5-10 weeks: $2^{\text {nd }}$ action)

In the first step, two researchers and one researcher worked together to share the contents of reflective journal writing, in-depth interviews, and professor observation logbooks in order to grasp the factors of stress common to both doctoral students. The contents were analyzed. In order to secure the reliability, a quantitative score of stress was calculated for each sub-region and the total score before and after the overcoming measures were implemented using the job and academic stress measurement tools (Table 2).

Table 2. Stress, Stress Response, Overcoming Power: Pre-Post-quantitative analysis

\begin{tabular}{|c|c|c|c|c|c|}
\hline \multirow{3}{*}{ Factor } & \multirow{3}{*}{ Sub-factor } & \multirow{2}{*}{\multicolumn{2}{|c|}{ Kwak Ji-min }} & \multirow{2}{*}{\multicolumn{2}{|c|}{ Total score (Mean) }} \\
\hline & & & & & \\
\hline & & Pre & Post & Pre & Post \\
\hline \multirow[t]{5}{*}{ Stress } & Private & $34(2.27)$ & $12(0.8)$ & $47(3.1)$ & $27(1.8)$ \\
\hline & Inter Personal & $12(2.4)$ & $5(1)$ & $12(2.4)$ & $9(1.8)$ \\
\hline & Study & $32(3.2)$ & $22(2)$ & $34(3.4)$ & $30(3.0)$ \\
\hline & Environment & $18(2)$ & $8(0.9)$ & $25(2.7)$ & $13(1.4)$ \\
\hline & Total & $96(2.46)$ & $47(1.2)$ & $118(3.0)$ & $79(2.0)$ \\
\hline \multirow[t]{8}{*}{ Stress Response } & Tension & $10(1.67)$ & $5(0.83)$ & $17(2.8)$ & $10(1.6)$ \\
\hline & Aggression & $1(0.25)$ & $1(0.25)$ & $3(0.7)$ & $0(0)$ \\
\hline & Body Reaction & $3(1)$ & $0(0)$ & $8(2.66)$ & $6(2.0)$ \\
\hline & Anger & $9(1.5)$ & $6(0.7)$ & $19(3.1)$ & $11(2.2)$ \\
\hline & Depression & $14(1.75)$ & $6(0.75)$ & $16(2.0)$ & $16(2)$ \\
\hline & Fatigue & $11(2.2)$ & $7(0.88)$ & $16(3)$ & $12(2.4)$ \\
\hline & Frustration & $15(2.14)$ & $4(0.57)$ & $23(3.3)$ & $15(2.14)$ \\
\hline & Total & $63(1.61)$ & $29(0.74)$ & $102(2.6)$ & $82(2.1)$ \\
\hline \multirow{3}{*}{$\begin{array}{l}\text { Overcoming } \\
\text { Power }\end{array}$} & Personal Ability & $86(5.0)$ & $91(5.35)$ & $91(5.3)$ & $94(5.5)$ \\
\hline & Acceptance of Life & $34(4.25)$ & $42(5.25)$ & $44(5.5)$ & $43(5.3)$ \\
\hline & Total & $120(4.8)$ & $133(5.32)$ & $135(5.4)$ & $135(5.48)$ \\
\hline
\end{tabular}

As shown in Table 2, the pre-score for stress and stress response was high, but the post-test showed a low score. Also, the ability to overcome stress has been shown to have a higher post score than the pre-score. In this regard, it can be seen that the chosen method to relieve stress has proved effective

In the second step, we try to find ways to cope with stress. To do this, participants share information about how to deal with each other's stress and finally choose the appropriate method for them

In the third step, we accept the opinion that the daily pattern of living is repeated every week, and check the schedule to overcome stress by adjusting the daily schedule and aptitude.

In the fourth step, we identify the problems and improve and supplement them after first implement the selected coping methods. Based on this, the second action is carried out. The action process takes place for a total of four weeks, two weeks for each of the first and second runs.

\section{Action, Reflection, Modification and Complement}

\subsection{First Action, Reflect, Modification and Complement}

In the first run, we started to apply the selected stress relief method while checking the weekly routine which is repeated weekly. The process in the first run is shown in Table 3 and Table 4.

Table 3. Selected Method

\begin{tabular}{ll}
\hline 1 week & $\begin{array}{l}\text { Resolving methods - Selecting a resolution method - Creating a weekly schedule } \\
\text { for each person - Deciding on a time for implementing a resolution method } \\
\text { suitable for your personal schedule }\end{array}$ \\
\hline 2 to 5 weeks & Running the solution - Reflect -Modification and Complement-Run \\
\hline
\end{tabular}


Table 4. Selecting Stress Relief Method

\begin{tabular}{ll}
\hline Kwak, Ji -min & Travel, exercise, and study in cafes. \\
\hline Park Joo-yeon $\begin{array}{l}\text { Getting support from husband to relieve stress, getting started early in the } \\
\text { morning, exercising }\end{array}$
\end{tabular}

\subsubsection{Park, Joo-yeon}

Park, Joo-yeon's main problem was that she could not cope with academic stress properly. As a result, academic performance has become less efficient and psychologically less effective. She is not doing his job as well as his previous academic career. It is too difficult because of worries about the future and problems in nursery school that arise constantly. It is time to learn various ways to work efficiently, manage grades, and study as a researcher. Therefore, she was chosen as three solutions to relieve stress: getting adequate emotional and physical support from her husband, getting up two hours earlier than usual for study and exercise.

- Need more action than words.

Getting support from her husband was effective at first. The main driving force was the expression of encouragement that she was doing everything well in spite of her hard times. However, the amount of work charged to her has not decreased, so fatigue and stress have not been relieved.

The husband, who watched me get angry and depressed, asked for a conversation. Through the conversation I asked my husband to actively express when I was sitting at the computer and studying. You suffered! You're doing great! He tried to hug and say. It was very effective at first. But, over the time, the husband's comforting words were ineffective. The amount of my work did not decrease. So, it was not a real comfort. (Park, Joo-yeon's journal writing, 10,3)

Over the time, his warm words and behaviors did not help me. The psychological comfort of the husband and wife is the most important factor of life, but it was thought that it is difficult to actively improve the stress to the study only by this method. (Park, Joo-yeon's journal writing, 10, 3)

- Woke up at dawn and had a free time.

It was very desirable to start the day on a leisurely schedule in the morning. It was hard at first, but as time went by, she could have room to think well in the morning and relax herself. She found it more efficient to get up early in the morning and start the day meditating and refreshingly. She plans how to spend the day in the morning and practices it. And in the evening she looks back on that day and goes to bed early to get up early tomorrow. It is much more significantly important that she using morning time rather than night time helped to revive stress.

I was studying at night and my family was always sleeping. It is difficult to do well in school life and work without relieving fatigue. It was difficult. Even though I studied late, I had to get up early to prepare your family breakfast. I want to get out of this situation. Something has to change. I decided to go to bed at night to get up early in the morning. Unlike so far, he goes to bed before 11 p.m. and practices waking up at 4 a.m. for several days. I woke up early in the morning and felt like a long day. In the morning I could afford to study, exercise, and prepare breakfast. It was really good! (Park, Joo-yeon's journal writing, Oct, 23)

I got up early in the morning, gave worship, and started the day. I feel much better than I thought and the day is really long. There are more good ideas than bad ones in the morning. I think I know a little bit why people should be morning people. I am tired because I am not used to it now, but if I become a habit, I will be able to manage my time more efficiently than spending hours at night. (Park, Joo-yeon's in-depth interview, Oct, 23)

- Need to have physical strength to study

In addition, she doesn't have time to exercise. She spent a lot of time sitting in a chair for nursery school work, doctoral studies, and course research. Her day is a stretch of tension. Recently, she has gained more weight and felt more tired than before she started her doctoral course. So she chose to exercise as a way to relieve stress.

I have participated in the PT program six times. I participated in the exercise using the evening hours of 1-2 days during the week and decided to exercise on Saturday morning if nothing special happened. At first, stretching was difficult. But the more I repeated it, the more stretching as well as other exercises were not difficult. I feel lighter. (Park, Joo-yeon's journal writing, Oct, 19)

When I went to the supermarket, I walked as much as possible and tried to stretch it at home when I had a chance. I drank a lot of water during my exercise. I feel less fatigue than usual and seem to be concentrating. 
My whole body was sore the next day after too much muscle exercise, but I didn't want to give up the exercise. Because I have to do a lot of physical work as well as academic work. (Park, Joo-yeon's journal writing, Oct, 23)

Park Joo-yeon, who is especially mindful and tries to be careful about small things and is trying to be perfect, has a lot of worries and anxiety. Because she was exhausted from the relationship with many people. Thus she was decided to exercise this method consistently not only for the body but also for the mental health.

\subsubsection{Kwak, Ji-min}

Kwak, Ji-min is tired from the fact that he is in charge of many roles such as time lecturer at universities, English lecturer at the center, and private piano lessons, and also has to spend more time in her studies than other students. Therefore, she chose travel, time management, and exercise as ways to cope with stress, based on the belief that we needed a resting tiredness in the combination of work and schoolwork.

- Travel is a happy healing.

Kwak, Ji-min was tired of work and study and needed a change. She chose to travel away from all her worries and worries to restore her tired body and mind. She didn't take her laptop with her to be a real rest for the trip and tried to turn off her cell phone if possible. Through this her journey became a free soul, and she herself had enough rest. In short, she had a full break on her own.

The Chuseok holiday began. During my last Chuseok trip, I remembered how I turned on my laptop in a hotel room and prepared class presentation. Let's get away from all work and study on this trip! Shake everything off and let's enjoy it! Laptops, papers, and class materials became lists that should not be taken on the trip. I did not have a tight schedule because it was a trip to relieve stress. If I want to sleep, sleep. Let's do what I want! (Kwak, Ji-min's journal writing, September 30)

I went to volcanic island and drank coffee. I enjoyed this time. I was liberated from the smartphone and took a walk and enjoyed the natural scenery. It felt like everything was hard to forget, but it was the happiest and most healed trip since the beginning of this semester. The reason is that I am not just doing something, but resting for me. (Kwak, Ji-min's journal writing, Oct. 16)

Kwak, Ji-min, always tired of work and study, enjoyed traveling since middle school. She has traveled a lot of countries with her father's active support, but since returning from Korea to Canada, She has had difficulty in traveling for herself. She was busy with study and work rather than traveling. However, this trip was not just a sightseeing tour for her, but it made her feel like a real trip.

- Let's have a cup of coffee

She doesn't always drink coffee, but she likes to drink coffee a day. She didn't have time for coffee. She checked her week-long schedule and found that there was an hour's break between the lecture and the lecture. So she decided to drink coffee at a cafe rather than study in a library or an empty classroom.

I really cannot rest an hour a day? I checked my schedule and found a day... Thursday! It is a day of teaching and lecturing in the school for 8 hours. I stayed at the campus for an hour between lectures and lectures. I thought that this time is also an extension of the lecture. Therefore, I prepared classes or prepared papers during this time... I changed my mind. As soon as the lecture was over, I left the school building and ran to the cafe. It was as if I was somewhat deviated somewhere. The word 'stress' did not come to my mind, and I started to have a happy hour of drinking coffee and thinking about what to do for two hours. Strangely, however, I felt like I was relieved of my stress. (Kwak, Ji-min's journal writing, Oct. 23)

Kwak, Ji-min checked each day's work closely instead of excuse not having time. She tried to find a spare time by looking closely at her work every week. As a result, she found leisure time. She knew there was one hour break between the lecture and the lecture. During that time, she did not stay on campus and found another way. Staying on campus all day and studying and worrying about classes are stressful. So she tried to take a break from campus for a while. She drank her favorite coffee to relieve boredom and relax. She does not need to study only in libraries or schools. There are many professors who are looking for a cafe near the laptop. When a lot of work is stressful, a cup of coffee can help. She did this.

- Start exercising to overcome immune deficiency.

Kwak, Ji-min, who has been suffering from persistent fatigue and stress, started to have a rash all over her body and became inflamed. It was a food poisoning. As the immune system is a symptom of stress, she decided to exercise to 
make her body healthier.

Finally my body is over. I have a red urticaria. I was sick a lot. I was afraid. Fortunately, the doctor said it was an immune deficiency symptom. The doctor told me to eat and rest and exercise. I went to the fitness club as soon as I finished my class on Saturday afternoon. (Kwak, Ji-min's journal writing, Oct. 8)

I complained that I didn't have time, but I went to exercise three times a week. After 12 hours of work, its 9 or 10 p.m. usually, it is time to go home, take a shower and sit on the computer. But unlike as usual, I went for exercise. I was walking on a treadmill, and I forgot everything while exercising, listening to music, watching TV. It was a real excuse to have no time. (Kwak Ji Min's Journal writing, Oct, 23)

Kwak, Ji-min has done this despite physical and mental difficulties over the past three and a half years... She was always spinning only a sieve wheel to alive like a squirrel, and in her repeated daily life she was so exhausted that she could find no reason why she should do these things. Everything was not pleasant. So she is looking for new enjoyment in her new attempt to relieve stress rather than simply focusing on relieving stress.

\subsection{Secondary Action, Reflect, Modification and Complement}

After five weeks, the result of the implementation of the overcoming measures for the second run was analyzed and the second plan and execution were made after finding the individual improvement plan through the score analysis through the measurement tool.

Table 5. Doctoral Students' Reflect, Modification and Complement

• After about 5 weeks, I began to feel uneasy about having a cup of coffee and
doing nothing. During these two hours, I decided to do homework and
lessons rather than just sit around in a daze. So, instead of drinking coffee at a
cafe and sitting around in a daze, I prepared a class by drinking coffee at this
time.
- Another stress was that exercise should be done in time. It was hard to go to
exercise like homework, but I felt like I had to go without missing it. So, I
decided to forget everything while watching TV while exercising. Exercising
and relieving stress are like catching two birds with one stone!
- I decided to change my mind. I didn't want to miss the time by moving to
my car in time for class. However, we decided to enjoy the scenery of fall
leaves, flowers, mountains and rivers while listening to music. As I changed
my mind, the scenery outside the window began to come into my eyes.
•The emotional support of the husband's words and gestures is no longer
effective. Rather, She tried to reduce the workload. The husband decided to
throw away food waste, clean up recycling, and bring his daughter to dinner
to walk the dog. The work load at home has been greatly reduced.
• Getting up early in the morning and planning a day and having a QT time
helped a lot and decided to go on.
• Increased exercise time.

\subsubsection{Park, Joo-yeon}

For a moment, support for Park, joo-yeon's husband gave him joy and strength, but she realized that there was something she had to do. So she tried to improve her work in a way that would reduce her workload. Getting up early in the morning and quietly reading the Bible, meditating and starting the day helped to overcome stress. She studied better in the morning than at night. The same goes for exercise. At first, it was difficult to exercise, but as time went by, she became used to her body, and it helped her body as well as her mental health and concentration.

My husband's support was psychological comfort, but it didn't help my work. On the contrary, it seemed that it was just lip service, and over time encouraged people to rest their bodies and minds, but it is difficult to have such a time in a given situation. So I decided to talk to my husband again and share the burden of work with each other. I decided to do the housework together and take my daughter in turns. If they couldn't pick up each other's daughter, they asked her to take a taxi. I want to live by breathing, too. I wanted to get out of my 
obsession to be a good mother in the future." (In-depth interview with Park, Joo-Yeon, Nov, 20)

Even if you are lazy, the more you continue to exercise, the more time you spend exercising. After exercising, I felt better and felt proud to spend time for my health. A sense of pride arose. I think I've lost weight. I feel good! Try to walk as much as possible. (Park, Joo-Yeon's journal writing, Nov. 23)

Park Joo-yeon face lit up in class. Though relatively expressive compared to other students, they often react nervously when their faces suddenly darken. But she changed. Now actively participate in the debate and share opinions well. She thanked her husband for his support. Unlike the first time I saw her, she looked happy. (Professor Observation journal, Nov, 27)

5.2.2 Kwak, Ji-min

Kwak, Ji-min traveled to relieve stress, tried to drink coffee from time to time between lectures and lectures, and did both travel and exercise, but the effect of this method was only two weeks. Things haven't changed. She felt uneasy just doing nothing while drinking coffee. She was so tired that she sometimes fell asleep while driving. She has to study her doctorate and teach at another school. It was still hard. She relieved her stress by exercising and traveling. She drank coffee at the cafe. Returning from her overseas trip, she returned to work to teach and study students. She is exhausted. She caught a cold for three weeks because of her lack of immunity. So she changed her way. Instead of traveling during the semester, she decided to take a lecture and see the scenery outside the window. She decided to study and prepare for a lecture while drinking coffee.

Although I was happy to prepare for the trip, I started looking for a one-day trip because I could not travel again during the semester I decided to go to places I had never visited, such as the Jinju Hanok Village and the Southern Sea and Germany Village, whenever I had a day. Also, the brief moments when I see blog posts about travel destinations worth going on during the vacation have given me a lot of excitement and happiness... (Kwak, Ji-min's journal writing, Nov, 13)

Leaving campus and studying in a cafe was much better than studying in a library. So, if I could spare an hour between lectures and lectures, I went to a cafe the next day to prepare for class. I felt that staying on campus was an extension of my work, but I didn't feel that studying at a cafe was an extension of my work. It's amazing that a cup of coffee can comfort me. (Kwak, Ji-min's in-depth interview, Nov. 13)

The first two weeks of P.T. Exercise was really fun. It felt good to think it was an investment for me. It was a good time when the thoughts of study and work could be put aside for a while and devoted to other things. But I found myself going to the gym because I thought I had to go no matter how hard it was. The previous day's exercise, which required two hours of driving, led to drowsy driving. So I decided not to exercise the day before the lecture. I exercised only on the day before I didn't drive for a long time because I didn't have a lecture. After implementing this method, I became less tired and enjoyed the outside scenery than dozing off driving. (Kwak, Ji-min's journal writing, Nov,.15)

\section{Discussion and Conclusion}

The Stress is the physiological, psychological and social state (Kim, Shim, Yang, \& Gil, 2005) caused by the imbalance between individuals and the environment. Park, Joo-yeon chose internal and external methods to overcome such stress. Internal resources tried to overcome stress on their own by choosing to use more morning time than night time to solve exercise and study problems. Moreover, through his husband's words or attitude of encouragement, he chose an external way of reducing the amount of work by sharing emotional support and housework. In contrast to Park, Joo-yeon and Kwak, Ji-min chose to deal with internal support rather than external pressure. The methods she chose were travel, exercise, and her studies and preparation for lectures in cafes. By implementing these methods, she became a little more relaxed than before. In particular, Dostoevsky was delighted after his harsh prison life that drinking tea alone and eating alone was a necessary condition for normal survival. This remark by Dostoevsky means a lot to us, living in a relationship with many people. Taking time alone is also important to relieve stress. The results of a quantitative analysis conducted by two Korean doctoral students after the stress control method are also proving this fact. After implementing selected methods to overcome stress, they have freed individuals and individuals from stress, aggression, anger, depression, fatigue and frustration, and have shown positive effects on schools and the environment. It also showed effects on stress response and coping skills. It is quite clear that they have both personal ability and overcoming power in life.

In the end, two Korean doctoral students in early childhood education successfully understood and accepted themselves through such a stress response, and self-praise life became a positive view of the world. What I realized 
by watching the implementation process for coping with stress is: Enjoying flowers and foliage, leaving footprints on the snow or on the beach, I was surprised to find that taking a short rest is how to overcome stress. Everyone can do it, and we know it too well, but we're missing something as easy as this. The fact that people feel more skeptical about what they are doing, and have more anxiety due to their lack of immersion has broken the balance of a neutral immersion mind. As a way to overcome this problem, it is necessary to constantly check on "If you want to live for me, what do you want to do?" and to take into account your own characteristics, such as stress response strategies and time management.

As Kim and his colleagues (2011) reported, the analysis of related factors of job stress revealed that difficulty of studying and fatigue influenced job stress, especially time shortage. Stress can be reduced or eliminated by the efforts of those who receive it. Therefore, coping strategies are required (high score, 2011). But above all, mind control is important for early childhood education and doctoral students to lead a satisfying life for them. As John Gordon (2017) wrote in "The Word of Life," "Life is not easy to be positive, but you are positive because life is difficult," they were moved by the way they controlled themselves to change their cool-headed minds and have positive minds. Yes, they have come all the way here with the determination and enthusiasm to study under these difficult circumstances, and the stress has increased. Fortunately, however, they have excellent coping skills. I got a message from Park, Joo-yean while I was preparing for class.

I can't go to school today because my teacher suddenly has a problem. The childcare information center said that it can receive assistance from an emergency substitute teacher from 2 p.m. The children are uneasy because the teacher is not here. I have to go into the class instead of the teacher. I'm really sorry (Park, Joo-yeon, Messenger, Oct, 6)

Something unexpected has happened, so don't be impatient and take good care of the children. Cheer up! Do not be in a hurry and take care of it slowly, as sudden things happen unexpectedly. Cheer up! (Professor, Messenger, Oct, 16)

This is common for early education majors. If the teacher fails to come to work unexpectedly, the director cannot attend school classes and deal with the problem. In some cases, the principal should take classes instead of the teacher. Of course, you can get a substitute teacher at the Children's Information Center, but if something like this happens all of a sudden, it's hard to find a substitute teacher. It is necessary to consider the circumstances of these students. You can't attend class even if you want to. It is important to understand and consider the different professional characteristics of each major as a way to lower the stress level of doctoral students who combine academic and professional life. In conclusion, as was way to reduce the stress of Korean doctoral students who combine academic studies and careers, I would like to suggest understanding, warm encouragement, and teaching on different job related characteristics in each major. Isn't this also a way to help them overcome their stress? However, this study has the limitation that the size of the population is only two Korean doctoral students, For this purpose, further studies on different large group samples are needed.

\section{References}

Baumeister, R. F. (1984). Choking under pressure: Self-consciousness and paradoxical effects of incentives in skillful performance. Journal of Personality and Social Psychology, 46, 610-620. https://doi.org/10.1037/0022-3514.46.3.610

Castle, J. B. (1997). Toward understanding professional development: Exploring views across a professional development school. Teachers and Teaching: Theory and Practice, 3(2), 221-242. https://doi.org/10.1080/1354060970030205

Denzin, N. K. (1989). The research acts (3rd ed.). Englewood Cliffs, New Jersey, NJ: Prentice Hall.

Dirkx, J. M. (1989, March). Self-reflection in the clinical experience: Using group processes to improve practitioner-client relationships. Paper presented at the annual meeting of the American Educational Research Association, San Francisco.

Germain, C. B., \& Gitterman, A. (1986). The life model of social work practice. New York, NY: Columbia University Press.

Huang, X., Iun, J., Liu, A., \& Gong, Y. (2010). Does participative leadership enhance work performance by inducing empowerment or trust? Journal of organizational behavior, 31, 122-143. https://doi.org/10.1002/job.636

Hwang, S. Y. (2017). John Gordon, life word. Seoul: Korea Management Association Consulting. 
Kang, B. G., \& Kim, C. Y. (2000). Development of a stress response scale. Korean Neuropsychiatric Association, 39(4), 707-719.

Kim, Y. H., Yang, E. S., Lee, S. Y., \& Gil, J. (2005). Human behavior and social environment. Seoul: Bong Sung Won.

Kim, Y. Y., Kim, J. H., \& Lee, C. H. (2011). Job stress level and related factors of remote college students with occupation. Lifelong Learning Society, 7(2), 157-174. https://doi.org/10.26857/JLLS.2011.08.7.2.157

Lee, Y. S. (2002). A Study on the New Direction of Field Research - Five Types of Field Research Practice and Practice. Educational Anthropology Study, 52(2), 83-114.

McCleese, C. S., Edy, L. T., Scharlau, E. A., \& Hoffman, B. H. (2007). Hierarchical, job content, and double plateaus: a mixed-method study of stress, depression and coping responses. Journal of Vocational Behavior, 71(2), 282-299. https://doi.org/10.1016/j.jvb.2007.05.001

Naughton, G. M., \& Hughes, P. (2008). Doing action research early childhood studies: a step-by-step guide. UK Open university press. Psychology, 55, 534-541.

Park, J. Y. (2011). Factors Affecting Stress, Stress Response and Coping Ability in Nursing Students. Thesis of Master's Degree at Seonam University.

Park, S. Y., \& Park, J. A. (2000). Educational organization theory. Seoul: Educational science history.

Song, Y. S. (2004). Factors Affecting Resilience of the Physically Handicapped. Kohshin University Master's thesis.

Wagnild, G. M., \& Young, H. M. (1993). Development and psychometric evaluation of the resilience scale. Journal of Nursing Measurement, 1(2), 165-178.

Yoo, J. S., Chang, E.W., \& Park, J.W. (2008). Development of stress measurement tools for Korean nursing students. Korean Journal of Nursing, 38(3), 410-419. https://doi.org/10.4040/jkan.2008.38.3.410 